is concluded that inorganic sulphates are covalently bound in the vapour state.

Special interest is attached to the spectrum of ammonium nitrate in the vapour state. It exhibits a diffuse maximum at $262 \mathrm{m \mu}$ with a long wave limit at $299 \mathrm{~m} \mu$, and hence appears to be bound covalently in the vapour state, as are all the other inorganic nitrates investigated earlier. This indicates a structural formula such as

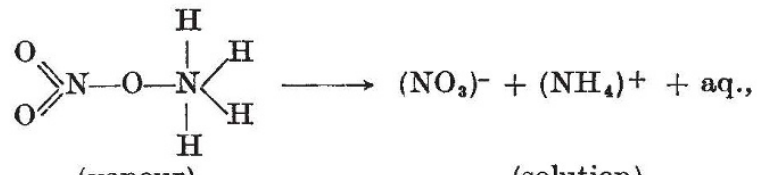
(vapour) (solution)

with five covalent bonds in the vapour state, in contradiction to the covalency maximum of four, introduced by Sidgwick on the basis of the octet theory.

A detailed report will be published in the Proceedings of the Indian Academy of Sciences (Bangalore).

Department of Physics, M. IsRarul Haq. R. SAMUEL. Muslim University, Aligarh.

1 NATURE, 137, 496 (1936).

S. M. Karim and R. Samuel, Proc. Ind. Acad. Sci. (Bangalore), 1, 398 (1934).

\section{Isotope Displacement in the Arc Spectrum of Platinum}

WE have been engaged for some time upon the study of the fine structures of thirty-three lines of the arc spectrum of platinum in the region $\lambda \lambda 6800$ 4320. We find that the odd isotope, 195, has a nuclear spin of $\frac{1}{2}$, and that all the terms observed by us exhibit regular even isotope displacement, the lightest isotope lying deepest. The approximate abundance ratios of the four observed isotopes, 198, 196, 195 , 194, are $1: 4: 4: 5$. Jaeckel and Kopfermann ${ }^{1}$ have just recently published fine structure measurements of $46 \mathrm{Pt} \mathrm{I}$ lines in the region $\lambda \lambda$ 5900-2350. They also find that the spin of 195 is $\frac{1}{2}$ and report the values of the even isotope displacements in 27 terms. Eight of the lines measured by J. and K. are amongst those studied by us and both sets of measurements are in good agreement.

Even Isotoph Displackments In the PT I SPECtrum

\begin{tabular}{|c|c|c|c|c|c|}
\hline Term & Authors & $\mathrm{J}$. and $\mathrm{K}$. & Term & Authors & J. and $\mathbf{K}$. \\
\hline 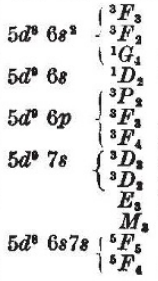 & $\begin{array}{r}199 \\
200 \\
93 \\
116 \\
35 \\
57 \\
\sim 15 \\
\sim 23 \\
2 \\
2 \\
\sim_{0}^{107} \\
107 \\
107\end{array}$ & $\begin{array}{r}123 \\
37 \\
55 \\
\sim 40 \\
15 \\
12 \\
\sim 100 \\
\sim 100\end{array}$ & $5 d^{8} 686 p \mid \begin{array}{ll}55 D_{4} \\
5 G_{5} \\
5 D_{3} \\
5 G_{8} \\
D_{1}\left(X_{1}\right) \\
D_{3}\left(Y_{8}\right) \\
D_{8}\left(Z_{8}\right) \\
5 F_{3} \\
5 F_{4} \\
5 D_{2} \\
D_{2}\left(13_{2}\right) \\
D_{3}\left(17_{8}\right)\end{array}$ & $\begin{array}{r}\sim 76 \\
107 \\
\sim 45 \\
107 \\
83 \\
50 \\
\sim 13 \\
109 \\
107 \\
\sim 25 \\
107 \\
107\end{array}$ & $\begin{array}{r}85 \\
47 \\
45 \\
116 \\
\sim 50\end{array}$ \\
\hline
\end{tabular}

The terms observed by J. and $K$. belong to the $5 d^{9} 6 s, 5 d^{8} 6 s^{2}, 5 d^{8} 6 s 6 p, 5 d^{9} 7 s, 5 d^{9} 6 p, 5 d^{8} 6 s 7 s$ and $5 d^{10}$ electron configurations, and from already established data on even isotope displacement they justifiably assume the displacement in $5 d^{10}$ to be approximately zero. This enables absolute displacements to be determined.

We have measured even isotope displacement in 25 terms and obtained relative values based upon the assumption that the displacement in $5 d^{9} 7 s^{3} D_{2}$ was zero. The measurements of $\mathbf{J}$. and $\mathbf{K}$. show that a slight adjustment is necessary for they give $12 \mathrm{~cm} .^{-1} \times 10^{-8}$ as the absolute displacement for this term. This absolute value is adopted by us and we find that our displacements are in very good general agreement with those of J. and K. The important confirmatory fact that there is agreement between both sets of relative displacements is, of course, independent of the slight adjustment.

The accompanying table gives a comparison of our values with those of $J$. and $K$. Displacements are given in $\mathrm{cm}^{-1} \times 10^{-3}$, and in all cases the three even isotopes are approximately equidistant, 194 being deepest.

Attention may be directed to the fact that Pt 195 ( $\operatorname{spin} \frac{1}{2}$ ) is an atom with an odd nuclear neutron, and, as has been shown by one of us $^{2}$, the spin value of $\frac{1}{2}$ occurs more frequently in this type than any other spin value. Further evidence on this point is being published in another note.

We shall shortly publish elsewhere a fuller discussion together with an analysis of the fine structure interval factors in the terms of the 195 isotope.

$$
\begin{aligned}
& \text { Physics Department, } \\
& \text { University of Manchester. } \\
& \text { April } 15 . \\
& \text { E. LEE. }
\end{aligned}
$$$$
\text { S. Tolansky. }
$$

\section{Reported Occurrence of European Fishes on the Tavoy Coast, Burma}

MY attention has been directed to the letter of Mr. J. R. Norman in NAture of February 22 : as the collector of the material in question, I feel it desirable to recapitulate the facts.

At Maungmagan in 1933, I made an extensive collection of fish, some being purchased from the boats before the cargo was landed, some from fishermen standing and casting nets in the waves, the majority collected by myself personally. On arrival at Rangoon, I ordered my laboratory steward to pack and dispatch them to the-Indian Museum. Dr. Hora has already stated that his museum possesses no material of European origin; any interpolation of strange fish must therefore have occurred in my department.

To the best of my belief, and after consultation of such records as are available, the department has neither purchased nor had given to it any specimens of European fish : though I am naturally not prepared dogmatically to exclude the possibility of error, it is difficult to see how the European forms could have intruded. I believe I can recollect the collection of a Cottus and a Blennius, but again memory, after the lapse of a year, is liable to be untrustworthy. If circumstances permit, at the same time at the same place this year I will make a further collection which may finally settle the dispute.

In conclusion, facts-or the sincere belief of the observer, whichever may be preferred-cannot be 